\title{
ACERCA DO LIMITE-DO-HOMEM: BART SIMPSON E BARTLEBY PROBLEMATIZAM OS CONCEITOS DE MORAL, NIILISMO E SUPER-HOMEM EM NIETZSCHE
}

\author{
R. MONTOITO*, R. A. ARAÚJO \\ Instituto Federal de Educação, Ciência e Tecnologia Sul-rio-grandense \\ xmontoito@gmail.com*
}

\section{RESUMO}

Este artigo problematiza alguns conceitos da filosofia de Nietzsche, utilizando-se dos personagens Bart Simpson e Bartbely como acionadores cognitivos. Agencia-se assim, desenho animado e literatura como formas de expressão do cotidiano, que podem potencializar o interesse dos alunos em uma problematização filosófica que é imanente aos produtos culturais que os cercam. Serão discutidos, com maior atenção, os conceitos nietzschianos de Moral, Niilismo e Super-Homem, bem como se prospectará a possibilidade do conceito de um Limite-do-Homem. Tais discussões são feitas tomando por base escritos de Deleuze, Guattari e Nietzsche.

PALAVRAS-CHAVE: Nietzsche; Moral; Niilismo; Super-Homem; Limite-do-Homem.

\section{ON THE MAN-LIMIT: BART SIMPSON AND BARTLEBY PROBLEMATIZE THE CONCEPTS OF MORAL, NIILISM AND SUPER-MAN IN NIETZSCHE}

\begin{abstract}
This paper aims to reflect on some concepts of Nietzsche's philosophy by using Bart Simpson and Bartbely characters as cognitive triggers. The main idea is to manipulate cartoon and literature as ways of everyday expression, which can enhance children's interest in a philosophical debate that is immanent to
\end{abstract}

the cultural products that surround them. The Nietzschean concepts of Moral, Nihilism and Superman will be discussed more carefully, as well as the possibility of a notion of the concept of Limit-of-Man. Such discussions are made on the basis of Deleuze's, Guattari's and Nietzsche's writings.

KEYWORDS: Nietzsche; Moral; Nihilim; Superman; Limit-of-Man. 


\section{APRESENTAÇÃO: AQUELA FAMÍLIA AMARELA DO SOFÁ}

Uma generalização parece sempre absurda, em todo o caso, gostaríamos de ter podido começar essa introdução dizendo que "todo mundo conhece Os Simpsons". Poderia parecer para o leitor um exagero desmedido, mas não há outra figura de linguagem que justifique os quase trinta anos que este programa está no ar. Estreia no Natal de 1989, no canal Fox americano e torna-se a série de TV com maior longevidade, dentre àquelas que ainda estão "no ar"; assim, ultrapassa outras séries longevas, que ainda fazem a alegria dos telespectadores atuais, como Grey's Anatomy (14 temporadas), Supernatural (13 temporadas) e Law and Order: Special Victims (19 temporadas).

Talvez, por ser um programa de animação, prestou-se mais facilmente a sair da TV para ocupar camisetas, cadernos, brinquedos, jogos de videogame, bonecos de pelúcia, miniaturas, canecas e todos os outros tipos de badulaques concebíveis e consumíveis. Se há quem não conheça os Simpsons, é provável que logo isso mude de uma forma ou de outra. Verifica-se facilmente que Os Simpsons constituem um programa popular porque muitos daqueles que nem eram nascidos em sua estreia, ou nos primeiros anos em que estava no ar, conhecem-no e identificam seus personagens.

Com o passar dos anos, Os Simpsons não foi somente satirizando a cultura existente em seus episódios, nos quais o telespectador mais atento pode reconhecer paródias de cenas de filmes conhecidos como $E$ o vento levou e Matrix, ou personalidades como Schwarzenegger e Elton John (nós, brasileiros, também tivemos nossa vez com a "simpsonização" do jogador de futebol Ronaldo e também com alguns episódios em que a família vinha passar férias no Rio de Janeiro); foi também extrapolando o seu universo para influenciar a cultura popular que se desenvolve fora do programa: outro seriado popular quando estava no ar, Lost, teve seus personagens divulgados como se pertencessem ao universo do desenho. A influência do programa é tão grande que é possível encontrar reproduções de capas de discos dos Beatles e do Nirvana ou obras de arte de Escher, Dali e Munch, entre outros, na forma Simpson-de-ser.

Devido a esta popularidade do desenho ${ }^{1}$, a família Simpson pode ser apresentada resumidamente: Homer é o pai barrigudo e amante de cerveja que trabalha na usina nuclear da cidade, Marge é a mãe amorosa e dona-de-casa, Maggie é a bebê que ainda não aprendeu a falar (se bem que suas atitudes substituem sua fala), Lisa é a obediente e inteligente filha do meio, e Bart, o filho mais velho, "não é o tipo de pestinha adorável que vive se metendo em encrenca; ele não é um rebelde com o coração de ouro. É, isto sim, um delinquente esperto, um 'bad boy' em calças azuis, um destruidor, um servo de satanás - se você acredita nesse tipo de coisa" (CONRAD, 2007 p. 65). A sociedade de Springfiel, cidade na qual moram, ainda é composta por outros diversos tipos únicos: o palhaço amargurado Kursty, o milionário esnobe Mr Burns, os vizinhos perfeitos Flanders, o diretor da escola Skinner, e tantos outros que deixam claro que "antes de mais nada, Os Simpsons é o retrato mais cínico e realista da sociedade americana (e ocidental, em geral) realizado até hoje" (BACHINI, 2007, p. 3).

\footnotetext{
${ }^{1}$ No Brasil, além de ser exibido pelo canal Fox da TV a cabo, Os Simpsons já passou nos canais Globo, SBT e Bandeirantes.
} 
Tomando como ponto de entrada deste nosso estudo a personalidade de Bart Simpson, investimos na possibilidade de que inseri-lo em sala de aula, como acionador cognitivo e potencializador, ou seja, como um intercessor (DELEUZE, 2010) do espaço-tempo de sala de aula, pode gerar uma profícua problematização e produzir como efeito "que a filosofia, considerada atualmente uma disciplina morta, tem ainda coisas a dizer sobre a sociedade de hoje" (BACHINI, 2007 , p. 3). Não queremos dizer, com isso, que outros estudos mais ligados aos textos originais dos filósofos, e que aulas mais tradicionais devam ser abandonadas, mas que também se pode sugerir uma abordagem que, embora diferenciada, não perde de vista as questões filosóficas, além de produzir outra "forma de expressão" (DELEUZE, GUATTARI, 1995b, 1997b) dessas questões.

\begin{abstract}
O essencial são os intercessores. A criação são os intercessores. Sem eles não há obra. Podem ser pessoas - para um filósofo, artistas ou cientistas; para um cientista, filósofos ou artistas - mas também coisas, plantas, até animais como em Castañeda. Fictício ou reais, animados ou inanimados, é preciso fabricar seus próprios intercessores. É uma série. Se não formarmos uma série, mesmo que completamente imaginária, estamos perdidos. Eu preciso de meus intercessores para me exprimir, e eles jamais se exprimiriam sem mim: sempre se trabalha em vários, mesmo quando isso não se vê (DELEUZE, 2010, p. 160).
\end{abstract}

Para construir a argumentação desse trabalho, assistimos às duas primeiras temporadas completas de Os Simpsons, num total de trinta e cinco (35) episódios (13 da primeira e 22 da segunda). Ainda que acreditemos que a personalidade de Bart não vai mudar até o final do programa, nosso olhar firma-se apenas nesta pequena parte. Os episódios foram vistos com legendas, a fim de que pudéssemos transcrever alguns diálogos como se passam na versão original (fato que algumas vezes é levemente alterado na dublagem) e, por isso, quando tivermos que nos referir a algum episódio em especial, fá-lo-emos citando seu título original ${ }^{2}$.

Tomando como "texto de partida" (CAMPOS, 2013) a personalidade do jovem Bart, tensionaremos a moral nietzschiana, o niilismo e a elaboração do Super-Homem, agenciando (DELEUZE; GUATTARI, 1995a, 1995b, 1996, 1997a, 1997b) fragmentos do filósofo com as atitudes e as falas do personagem.

\title{
2 NIETZSCHE E BART: CONFRONTOS COM A MORAL
}

A filosofia de Nietzsche marcou sua época e o tornou imortal. Crítico severo da sociedade, da família e da religião, pode-se dizer, em linhas gerais, que "embora Nietzsche rejeitasse e até risse do ideal tradicional da assim chamada 'boa pessoa', a pessoa solidária, religiosamente virtuosa, ele próprio tinha um desejo que tangenciava um ideal: o espírito livre; a pessoa que

\footnotetext{
${ }^{2}$ A notação usual que identifica os episódios de um programa entre os fãs é uma combinação numérica que expressa a temporada e o número do episódio, normalmente separados por um ponto. Deste modo, o primeiro valor indica a temporada do programa e, os outros dois, o número do episódio daquela temporada. Por exemplo: 1.05 identifica o quinto episódio da primeira temporada, 2.15, o décimo quinto episódio da segunda temporada, e assim por diante.
} 
rejeitava a moralidade tradicional, as virtudes tradicionais; a pessoa que abraça o caos do mundo e dá estilo ao caráter" (CONRAD, 2007 p. 66).

No início, sua obra foi fortemente influenciada por Schopenhauer (1788 - 1860), levandoo a promulgar a ideia de que a vida seria um sofrimento perpétuo, pois esta seria movida pelos desejos intrínsecos do homem, e estes, quando não sanados, causam uma imensa frustração; como o desejo é imanente (DELEUZE; GUATARI, 1995a , 2010) à vontade, o homem tende a experienciar um vazio, pois nunca há fim para o desejo e nenhuma satisfação por um desejo alcançado é suprema, levando, assim, o homem a um sofrimento perpétuo. Mas, após alguns anos, o filósofo abandonou Schopenhauer.

\begin{abstract}
Em seus primeiros escritos, Nietzsche propunha que o mundo era dividido em aparência e realidade, vontade e representação, uma visão que ele logo repudiou, afirmando que não existe nada mascarando o caos, nenhum ser por trás do ato. Agora, eis a consequência realmente interessante dessa mudança de posição: em contraste à visão anterior, na qual nós éramos meros fenômenos da vontade subjacente, projeções artísticas, obras-de-arte para a unidade primordial, que é a verdadeira artista e espectadora, somos agora tanto a vontade quanto o fenômeno, ou melhor, ambos são a mesma coisa. Assim, nós próprios nos tornamos artista, espectador e obra-de-arte, tudo em um (...). Nietzsche obliterou a distinção entre arte e vida. Consequentemente, já que é a existência como um fenômeno estético, uma realização artística, que é justificada ou redimida, Nietzsche parte da justificativa do mundo para a justificação individual. Como expressões da vontade - da vontade manifesta - somos um misto de artistas e obras-dearte, e assim nos justificamos, encontramos sentido para as nossas vidas, criando-nos a nós próprios por meio dessas expressões da vontade e por intermédio de nossas ações (CONRAD, 2007 p. 72).
\end{abstract}

Bart Simpson nunca foi - e nem faz questão alguma de ser - um bom aluno, mas parecenos que ele, de algum modo, adquiriu um movimento nietzscheniano; um devir-nietzschiano, visto que a todo tempo ele busca expressar sua vontade, e suas ações são planejadas para que se divirta e alcance determinado objetivo, sem se importar se estará ou não cumprindo os padrões morais da sociedade em que vive. E não é o caso de que suas ações erradas venham, depois, lhe causar algum peso na consciência ou aprendizado: ele as faz porque deseja fazê-las, porque deseja satisfazer sua moção interior, sem medir consequências, sem obedecer a regras e sem se importar com a opinião dos outros. Pode-se dizer, então, que, no desenho, Bart afirma (DELEUZE, 2001) o espírito livre do qual Nietzsche fala, implica-se com o que deseja, e não só abraça o caos, como também o cria, recodificando tudo isso para dar forma ao desejo que mais lhe apraz. Ainda que algumas vezes ele pareça sujeitar-se às tradições, tudo não passa de mais uma cena criada por ele; uma cena assinada pelo seu comum sarcasmo ou falsidade, como podemos destacar nos três diálogos que se seguem. 
Diálogo 1: neste episódio ${ }^{3}$, Bart causa confusão no dia de Ação de Graças ao destruir o enfeite de mesa criado por Lisa. Colocado de castigo, ele foge de seu quarto, deixando todos preocupados, e só volta tarde da noite.

Bart: Eles choraram?

Lisa: Sim.

Bart: Na mosca!

Lisa: Bart, por que você queimou meu enfeite?

Bart: Ah, qual é?

Lisa: Foi porque você me odeia ou porque você é mau?

Bart: Não sei. Não sei porque eu fiz e gostei ou porque vou fazer de novo!

Lisa: Mas me peça desculpas.

Bart: Por quê?

Lisa: A única razão para se desculpar é se você olhar dentro de si e encontrar uma mancha que não queria que estivesse lá porque se sente mal por ter me magoado.

Bart: Me deixe em paz.

Lisa: Vá olhar!

Bart: Tudo bem, tudo bem. Estou procurando pela mancha. Hum... hum... Estou checando ainda. Que idiotice. Não vou achar nada. Só porque quebrei uma coisa em que ela deu duro e eu a fiz... Oh, oh! Desculpe, Lisa.

Diálogo 2: neste episódio ${ }^{4}$, Bart quer ser tão destemido quanto o homem que pula de moto, num show, sobre um grande tanque cheio de tubarões. Para mostrar a todos sua coragem, ele resolve saltar de skate por cima da Garganta de Spriengfield ${ }^{5}$, e seu pai tenta fazê-lo mudar de ideia. $O$ garoto promete desistir do seu intento, mas não cumpre o prometido.

Homer: Olha, sei que não posso te impedir. Só posso te pedir para prometer que não vai.

Bart: Tá, eu prometo [Homer faz uma careta de desaprovação]. O que foi?

Homer: Não falou sério! Essa não é uma promessa que não espero que cumpra. Se prometer, terá que cumprir.

Bart: Por quê?

Homer: Senão, nunca mais vou acreditar em você.

Bart: Qual é.

\footnotetext{
${ }^{3} 2.07$ - Bart VS Thanksgiving. Apesar de, no final, ele acabar se desculpando (porque alguns desenhos têm, ao fim, algum toque de "lição de vida"), gostaríamos de ressaltar a frase em que ele diz que gostou do que fez e o fará outras vezes.

2.08 - Bart the Daredevil

${ }^{5}$ Uma espécie de Grand Canyon
} 
Homer: É sério, guri!

Bart: Tá, pai. Prometo. Não vou à Garganta de Springfield.

Diálogo 3: se passa num episódio ${ }^{6}$ em que Bart e dois amigos juntam dinheiro pra comprar a edição número um do "Homem Radioativo", seu super-herói favorito. Como depois os três sentem-se donos do gibi e, ao mesmo tempo, nenhum o é, eles acabam brigando até deixar o gibi estraçalhado.

Bart: Trabalhamos tanto, e agora se foi. Acabamos sem nada porque não sabemos repartir.

\section{Millhouse: $O$ que quer dizer com isso?}

Bart: Nada. Só me irrita.

A partir destes extratos, podemos ver que o jovem Simpson não supervaloriza instituições como a família e a amizade: o que ele quer mesmo é celebrar a intensidade de cada momento. Além disso, outras marcas sobressaem no percurso de Bart, inclusive quando ele subverte a moral de Springfield, como fica exposto nas frases que escreve no quadro-negro na abertura do programa - cada uma delas movimenta um castigo que o professor lhe impõe, acreditando que, de tanto as escrever, Bart acabará por mudar de comportamento. Ou seja, temos claramente uma situação em que a repetição funciona como dispositivo de sujeição, ao qual Bart resiste. Ledo engano pensar que Bart se submeteria a repetir algo, que não pudesse ele afirmar; e o que acontece é que ao escrever as frases "não vou arrotar em aula"7 , "não instigarei revoluções" ${ }^{8}$, "não vou mais desenhar mulher pelada na aula", "não vou mais chamar a professora de gostosa"10, "não encorajarei os outros a voarem"11, "não vou mais tirar xerox da minha bunda"12, "não vou arrotar o hino nacional"13, "não vou vender as terras da Flórida"14 etc. Bart assume uma posição de resistência, na qual a negação das atitudes reprimidas escrita repetidamente assume o papel de uma ironia aberta, em um movimento de transvaloração dos valores que lhe estão sendo impostos. Isso agencia (DELEUZE; GUATTARI, 1995a, 1995b, 1997b) uma relação que coloca à superfície a posição singular de Bart, que inegavelmente dá vazão aos seus desejos sem se preocupar com os efeitos, preferindo não se opor ao castigo, mas cumprindo-o ao seu modo, o que subverte a lógica punitiva em questão. Bart, como Bartleby ${ }^{15}$ (DELEUZE, 2011) desafia a ordem das coisas e, de algum modo ironiza o castigo negando a negação que lhe é imposta pela

\footnotetext{
${ }^{6} 2.21$ - Three Men and a Comic Book

71.04 - There's No Disgrace Like Home

81.06 - Moaning Lisa

${ }^{9} 1.07$ - The Call of the Simpsons

${ }^{10} 1.10$ - Homer's Night Out

${ }^{11} 2.01$ - Bart Gets an F

${ }^{12} 2.04$ - Two Cars in Every Garage and Three Eyes in Every Fish

${ }^{13} 2.14$ - Principal Charming

${ }^{14} 2.15$ - Oh Brother, Where Art Thou?

${ }^{15}$ Personagem criado por Herman Melville. Em português, diferentes editoras publicaram a história com títulos distintos: "Bartleby, o escrivão", "Bartleby, o escrevente" ou "Bartleby, o escriturário".
} 
escrita de uma negação que acaba por funcionar na prática como afirmação dos desejos que lhe estão sendo castrados.

Estamos misturando personagens tão diferentes quanto Ahab ${ }^{16}$ e Bartleby. No entanto, não são em tudo opostos? A psiquiatria melvilliana invoca constantemente dois polos: os monomaníacos e os hipocondríacos, os demônios e os anjos, os carrascos e as vítimas, os Rápidos e os Lentos, os Fulminantes e os Petrificados, os Impuníveis (para além de qualquer punição) e as Irresponsáveis (para aquém de qualquer responsabilidade). Qual é o ato de Ahab quando arremessa seus dardos de fogo e de loucura? É ele quem rompe um pacto. Ele trai a lei dos baleeiros, que consiste em dar caça a qualquer baleia sã que encontrem, sem escolher. Ele sim escolhe, perseguindo sua identificação com Moby Dick, lançado em seu devir indiscernível, colocando sua tripulação em perigo de morte. É essa monstruosa preferência que o tenente Starbuck the censura amargamente, pensando até em matar o capitão desleal. É pecado prometeico por excelência, escolher (DELEUZE, 2011, p.104)

Bart, assim como Ahab e Bartleby, resiste sem se opor, criando uma zona de indescernibilidade pela qual tensiona o castigo sem negar cumpri-lo; ele escolhe, o que efetivamente produz um ato de descumprimento que subverte a "palavra de ordem" (DELEUZE; GUATTARI, 1995b) Com isso, Bart continua a viver cada momento como se estivesse elaborando uma obra-de-arte, cujo valor ele vislumbra de maneira diferente dos demais.

Se todas essas frases a serem escritas repetidamente no quadro-negro são punições impostas a Bart, por que ele não aprende? Por que segue com seu mau comportamento? Como diria Nietzsche,

\begin{abstract}
O pensamento agora tão óbvio, aparentemente tão natural e inevitável, que teve de servir de explicação para como surgiu na terra o sentimento de justiça, segundo o qual 'o criminoso merece castigo porque podia ter agido de outro modo', é na verdade uma forma bastante tardia e mesmo refinada do julgamento e do raciocínio humanos; quem a desloca para o início, engana-se grosseiramente quanto à psicologia da humanidade antiga. Durante o mais largo período da história humana, não se castigou porque se responsabilizava o delinquente por seu ato, ou seja, não pelo pressuposto de que apenas o culpado devia ser castigado - e sim como ainda hoje os pais castigam seus filhos, por raiva devida a um dano sofrido, raiva que se desafoga em quem o causou (NIETZSCHE, 2009 p. 48).
\end{abstract}

Bart não aprende com tais castigos porque se sente livre a pensar do seu modo, mas também não se insurge contra o castigo em um ato de ressentimento, e escolhe seguir o seu curso, sem pesos e sem culpa. Uma vez que ele não reconhece seus atos como transgressores e sim como manifestações do seu desejo, o conceito de castigo se desfaz: ele não se incomoda nem com seus atos, nem com o castigo recebido, mas os seus atos incomodam os que já estão moldados a determinado comportamento e, somente por isso, por incomodar aos outros, é que ele é castigado. “O que em geral se consegue com o castigo, em homens e animais, é o acréscimo

${ }^{16}$ Personagem criado por Herman Melville em seu livro "Moby Dick". 
do medo, a intensificação da prudência, o controle dos desejos: assim o castigo doma o homem, mas não o torna 'melhor' " (NIETZSCHE, 2009 p. 66). Nesse caso, Bart prefere não se opor ao castigo, o que afirma uma posição que o coloca fora dessa sistemática de sujeição, por sua escolha.

Acontece que, no que tange a Bart Simpson, nem sua família, nem seus professores conseguiram - ou conseguirão - domá-lo. Mas, para que não caiamos no erro crasso de classificá-lo como amoral, é necessário que entendamos que a moral, para Nietzsche, é "só a argamassa que dá possibilidade para essa existência ontológica que temos" (COELHO; RODRIGUES, p. 5) de viver em sociedade. Neste sentido, "a moralidade não é específica do homem: todo o mundo animal é moral, pois nele o indivíduo subordina-se ao grupo" (SAUTET; BOUSSIGNAC, 1985 p. 98) ${ }^{17}$.

Por um escrúpulo que me é próprio, e que confesso de mau grado refere-se, com efeito, à moral, àquilo que até agora sobre a terra foi celebrado como moral -, por um escrúpulo que apareceu tão cedo, tão sem ser chamado, tão incontível, tão em contradição com ambiente, idade, exemplo, procedência, que eu quase teria o direito de denominá-lo meu "a priori" - teve minha curiosidade assim como minha suspeita, de fazer alto, temporariamente, diante da pergunta: que origem tem propriamente nosso bom e mau (NIETZSCHE, 2009, p. 8).

Para o filósofo, o bem, o mal e a moral são apenas termos estabelecidos que, muitas vezes, refletem as situações de poder e diferenças entre os fracos e os fortes, os ricos e os pobres, os que podem mandar e os que devem obedecer. É a luta entre a "moral dos senhores" e a "moral dos escravos". Contudo, faz-se necessário ter prudência na escuta das palavras de Nietzsche, como forma de promover uma escuta cuidadosa dessas palavras, que muitas vezes trocam de lugar, assumindo perspectivas e produzindo efeitos diferentes.

Precisamente o oposto do que sucede com o nobre, que primeiro e espontaneamente, de dentro de si, concebe a noção básica de "bom", e a partir dela cria para si uma representação de "ruim". Este "ruim" de origem nobre e aquele "mau" que vem do caldeirão do ódio insatisfeito - o primeiro uma criação posterior, secundária, cor complementar; o segundo, o original, o começo, o autêntico feito na concepção de uma moral escrava - como são diferentes as palavras "mau" e "ruim", ambas aparentemente opostas ao mesmo sentido de "bom": perguntemo-nos quem é propriamente "mau", no sentido da moral do ressentimento. A resposta, com todo o rigor: precisamente o "bom" da outra moral, o nobre, o poderoso, o dominador, apenas pintado de outra cor, interpretado e visto de outro modo pelo olho de veneno do ressentimento. Aqui jamais negaríamos o seguinte: quem conhecesse aqueles "bons" apenas como inimigos, não conheceria senão inimigos maus, e os mesmos homens tão severamente contidos pelo costume, o respeito, os usos, a gratidão, mais ainda pela vigilância mútua, pelo ciúme inter pares [entre iguais], que por outro lado se mostram tão pródigos em consideração,

\footnotetext{
${ }^{17}$ Outras idéias de SAUTET e BOUSSIGNAC estão esparramadas pelo texto, mas a maioria delas não pôde ser citada tal qual aparece no livro, ou referenciada, pois é uma obra escrita quadrinhos, o que impossibilita, assim, que seus trechos apareçam conforme as exigências das normas técnicas. No entanto, é-nos necessário divulgar o seu uso para esta pesquisa e o indicamos, prontamente, aos leitores iniciantes da obra de Nietzsche.
} 
autocontrole, delicadeza, lealdade, orgulho e amizade, nas relações entre si - para fora, ali onde começa o que é estranho, o estrangeiro, eles não são melhores que animais de rapina deixados à solta (NIETZSCHE, 2009, p. 28-29).

Bart, muitas vezes, consegue fazer a transição da "moral dos escravos" para a "moral dos senhores", ainda que, para isso, tenha que se fazer parecer, segundo o julgamento dos demais, um garoto "amoral". O episódio ${ }^{18}$ que deixa essa transição de Bart mais evidente é aquele em que ele enfrenta seu colega Nelson. Tudo começa quando Nelson, o espertalhão da escola, rouba os bolinhos que Lisa fizera. Bart tenta defendê-la, mas acaba levando uma surra de Nelson, tanto naquele dia quanto nos subsequentes. Nelson personifica os fortes, os que podem fazer o que querem e tem uma trupe de seguidores, que azucrinam os mais fracos da escola, espancandoIhes e roubando-lhes o lanche; Bart é, neste momento, o oprimido, subjugado a outro grupo de alunos da mesma escola.

Depois de alguns dias em que apanha ritualisticamente, Bart convoca todos os que são humilhados pela trupe de Nelson e forma um pelotão de combate: com muito treino e estratégias, eles acabam encurralando o espertalhão e seus comparsas e agredindo-os com uma saraivada de bexigas d'água. Esta revolta, este ato de vingança, não é o que se espera de um ser tomado pela moral estabelecida: esperar-se-ia que ele se mantivesse pacato, recorresse às autoridades superiores e esperasse algum tipo de ação interventora.

Conrad (2007, p.75) pondera, acerca do acontecido, que Bart "Por causa desse ressentimento por ser fraco, doente e maltratado, e ser incapaz de tomar qualquer medida, o 'escravo' reage, e grita. Não para o que é diferente, nobre, aquilo que gostaria de ser. Ele rotula o nobre de 'maligno' e, consequentemente, chama a si próprio de 'bom'” (CONRAD, 2007 p. 75). Nesse caso, podemos contestar a argumentação de Conrad, no sentido de que a noção de nobre, segundo Nietzsche, não repousa na força de opressão do outro, menos ainda na constituição de uma trupe de oposição a trupe de Nelson, o que só faria aguçar o sentido da reatividade implicada nessa ação. Assim, o que a primeira vista coloca Bart em uma posição de escravo em relação a Nelson, acaba por não se sustentar, à medida que Bart não reage a força opressora de Nelson e sua trupe, mas por sua vontade de potência (DELEUZE, 2001 ) desloca-se, no sentido de afirmar um outro modo de relação, pela qual deseja tornar-se senhor de sua situação.

Se pensarmos que na situação exposta, seguindo os conceitos estabelecidos por Nietzsche, Bart cumpria o papel do "escravo" pela perspectiva de Nelson, contudo, pela perspectiva do próprio Bart que afirma seu desejo de tornar-se senhor do seu destino, há uma clara a subversão das relações implicadas. Ou seja, a relação de senhor e escravo excede a linearidade da relação à primeira vista, visto que excede a ação e a reação de um sobre o outro. Para Nietzsche o senhor, torna-se senhor de si e do seu destino e não do outro; outro que se torna escravo de si e das concepções de outrem que o escravizam. Quando Bart aparentemente deixa a posição de fraco, e se torna forte, não é por tornar-se forte que se torna senhor e não mais escravo; Bart deixa de ser escravo e torna-se senhor pela afirmação de sua vontade de potência, que o leva a afirmar a diferença possível que retornará de sua atitude. Como efeito,

${ }^{18} 1.05$ - Bart, the General 
agora Nelson e sua trupe o temem, não por terem se tornado escravos de Bart, o senhor, mas por terem retirado as máscaras que os impedia de serem vistos como escravos; ou seja, Nelson e sua trupe, pela força de opressão ao outro, disfarçavam-se de senhores, mas nunca se distanciaram do rebanho que sempre os abrigou. Bart não deixa de ser bom para ser maligno; apenas afirma o que o lance de dados the proporciona e assume uma posição na relação em que os outros the passam a julgar como bom ou mau, contudo o senhor é senhor para além dos julgamentos mundanos de bem e de mal.

Há outras situações em que a moralidade do Bart ${ }^{19}$ Ihe traz, inclusive, ganhos: o fato de ser um aluno-problema e criador de confusões acaba por lhe dar direito a um intercâmbio na França ${ }^{20}$ (um exílio, como diz o diretor Skinner, mas quem não gostaria de ser exilado na França ao invés de ficar "preso" na escola?); quando Homer instala ilegalmente a TV a cabo, ele espera seus pais saírem de casa para ganhar dinheiro vendendo para seus amigos ingressos que dão direito a assistir aos canais adultos ${ }^{21}$; ao colar numa prova e tirar nota acima da média, Bart aproveita o status de gênio para ser transferido a uma escola diferenciada e, quando se dá conta de que não acompanhará seus colegas e que prefere voltar à sua antiga turma, consegue convencer o Diretor Skinner de que está usando uma útil estratégia de estudo ${ }^{22}$ :

Bart: Quero voltar pra a escola antiga.

Skinner: Não se lembra do tédio, da frustração, da depressão intelectual?

Bart: É... bom... sabe... mais ou menos. Achei que podia ir disfarçado.

Skinner: Disfarçado? Bart, estou curioso. Continue.

Bart: Eu podia fingir ser um garoto burro normal. Para estudá-los, ver o que fazem. Descobrir o que os faz funcionar.

Em nenhum dos episódios analisados, Bart arrepende-se das coisas que faz a ponto de mudar de atitude. É como se ele sentisse que não precisa mudar e que suas ações são corretas, apesar de transgressoras.

Essa, portanto, é a raiz da persona 'bad boy' de Nietzsche; esse é o motivo por que ele desdenha da tradição e da moralidade, despreza a maioria das coisas que a maior parte das pessoas fracas considera importantes, mas que, na visão dele, são perigosas, negam e difamam a vida. Consequentemente, ele nos aconselha a ir 'além do bem e do mal', ir além da 'moralidade do escravo', parar de transferir valores deste mundo e desta vida, e ter força e coragem para abraçar o caos da existência e de nossas vidas e criar delas algo que tenha sentido (CONRAD, 2007 p. 76).

\footnotetext{
19 Não estamos nos referindo aqui à moralidade social e estabelecida, mas também compreendemos, como já expusemos, que não podemos chamar o garoto de amoral.

${ }^{20} 1.11$ - The Crepes of Wrath

${ }^{21} 2.13$ - Homer VS Lisa and the Eighth Commandment

${ }^{22} 1.02$ - Bart, the Genius
} 
Ou seja, Bart e Bartleby têm uma proximidade de funcionamento, porquanto ambos afirmam a possibilidade que lhes é dada de participar das relações nas quais estão envolvidos, no sentido de que o que lhes potencializa excede o juízo ao qual a relação está sujeita; isso os transcende a uma posição de afirmação do que a vida lhes oferece, declinando assim da imagem representacional do que a vida deveria ser. Ambos, Bart e Bartleby "preferem não" se deixarem docilizar (FOUCAULT, 2009), mesmo à custa de uma imagem de transgressão e culpa que permite um julgamento sumário de quem os vê, e os nomeia.

Bart Simpson não é um transgressor na mesma medida de Nietzsche, entretanto no universo bidimensional em que se desloca, acontecem posições que transversam entre si. Bart e Bartleby não são como Nietzsche, mas devém com Nietzsche; ambos implicam seus deslocamentos em uma afirmação da vida, em um "sim" à vida, o que os faz declinar da posição metafórica de se fazer parecer com alguém dado como modelo, e afirmar a possibilidade de inventar um vir a ser. Em Bart não há autoridade que tenha o direito de impedir o seu fluxo de vida: ele desobedece à mãe ${ }^{23}$, debocha do patrão de seu pai ${ }^{24}$, expõe o Diretor Skinner ao ridículo ${ }^{25}$ e consegue até mesmo barganhar com Deus e o Diabo, convencendo-lhes de que ainda não é a hora da sua morte ${ }^{26}$. No entanto, nada é planejado: Bart se inventa recursivamente em cada relação da qual participa, como um modo de operação que desconstrói e reconstrói a todo tempo o seu conceito de moral pelo tensionamento de uma posição ética singular. Bart e Bartleby encarnam de Nietzsche, não as palavras ou os valores, mas um modo de funcionamento, uma energia de deslocamento, que os coloca na relação com matérias com as quais traçam a provisoriedade das linhas de uma vida. Ambos, Bart e Bartleby, com Nietzsche transversado em seus percursos, investem na invenção de encontros que possam dar vazão ao que Nietzsche propõe, talvez de modo "mais elevado", em sua filosofia: fazer da própria vida uma obra-de-arte, mesmo que muitos não estejam prontos a ler os percursos que escrevem.

\section{SUPERMAN ${ }^{27}$ E BARTMAN: COMO VIR A SER O QUE SE PODE (OU O ABANDONO IRÔNICO DO NIILISMO)}

Em uma interpretação possível de Nietzsche, o estágio superior da humanidade seria o Super-Homem. Esta posição poderia ser alcançada por aqueles homens comuns que, tendo dedicado seus esforços a fazer de suas vidas uma obra-de-arte, transcenderiam em suas ações e

\footnotetext{
${ }^{23}$ Isso acontece em vários episódios

242.05 - Dancin' Homer. Bart debocha de Mr Burns quando este não tem força para fazer um bom lançamento no beisebol.

${ }^{25} 1.02$ - Bart, the Genius. Bart faz uma caricatura do diretor, utilizando spray, no muro da escola.

${ }^{26} 2.10$ - Bart Gets Hit by a Car. Bart é atropelado pelo carro do Mr Burns e fica entre a vida e a morte.

${ }^{27}$ Nos textos originais de Nietzsche, a expressão que o autor utiliza é Übermensch. A primeira tradução de Assim falou Zaratustra para o inglês foi feita por Alexander Tille e publicada em 1896. Tille traduziu Übermensch como Além-do-homem. Thomas Common, em sua tradução publicada em 1909, traduziu Übermensch como Super-homem. Common foi precedido por George Bernard Shaw, que fez o mesmo em 1903, diferenciando Homem e Super-homem. Walter Kaufmann lamentou esta tradução, em 1950, por não ser capaz de expressar corretamente o sentido da palavra alemã über e promover uma eventual confusão com o personagem de histórias em quadrinho Super-Homem. Sua preferência foi traduzir Übermensch como Acima-do-homem. Os estudiosos continuam empregando ambos os termos e alguns acabam optando por utilizar o termo original alemão. O prefixo alemão über pode significar superioridade, transcendência, excesso ou intensidade, dependendo das palavras às quais se associa. O adjetivo übermenschlich significa sobre-humano, no sentido de estar além das forças humanas ou fora da proporção humana. Particularmente, somos mais atraídos pelo termo Além-do-homem, utilizando em algumas traduções brasileiras, mas aqui optamos por utilizar Superman como um contraponto literário a Bartman.
} 
conseguiriam viver sem as amarras sociais que, na opinião dele, cerceiam a vida humana. Esta parcela da humanidade estaria liberta da crença na Igreja, na vida após a morte, na reencarnação, na teoria do karma, no poder dos cristais etc., isto é, seria capaz de viver sem amarras. O Super-Homem seria aquele "capaz de se auto-superar, de criar a própria vida, através da arte, vista como forma suprema da existência" (BANCHINI, 2007, p.7). Contudo, reconhece o filósofo, nem todos teriam capacidade para alcançar esse estágio.

Para Bachini (2007), Bart não é o Super-Homem nietzscheniano, mas seria um representante do niilismo, pois ele

não consegue construir para si uma nova identidade que não seja baseada na reação à alguma coisa e fica, por isso, bem longe do ideal nietzscheniano da auto-criação. Aliás, Bart poderia representar o niilismo decorrente da perda dos valores tradicionais: ele representa o homem moderno que, reconhecendo que o mundo não tem o sentido que Ihe atribuía a religião, não vê agora sentido algum neste. Do ponto de vista de Bart, uma vez que nada tem significado, por que não fazer aquilo que deseja? O primogênito Simpson age como um rebelde não para destruir os valores das tradições (como fazia Nietzsche), mas porque lhe falta uma identidade completa (BACHINI, 2007, p. 9).

De igual opinião é Conrad, para quem o personagem

percebe que sua vida é caótica, e que ele é um "carinha confuso", que precisa de forma. $\mathrm{E}$, realmente, parece haver uma espécie coerente de estilo em seu caráter, mas a maneira como ele define a si próprio é em grande parte reativa, e isso, claro, é algo que Nietzsche jamais aceitaria. O que eu quero dizer é que Bart se define e forja sua identidade, não como algum tipo de afirmação triunfante de seus talentos e habilidades, não como uma miscelânea de elementos díspares, mas sim como alguém em oposição à autoridade (CONRAD, 2007 p. 77).

Nossa posição, no entanto, é contrária à posição de Conrad e Bachini: não podemos classificar Bart Simpson como um niilista, do mesmo modo que não podemos classificar Bartleby. O niilista é aquele ser que não vê sentido na vida e, por isso, não faz planos para o seu futuro, características bem diferentes das que observamos no personagem. Bart que quer fazer desafios radicais $^{28}$, ser famoso como o palhaço Krusty quando crescer $^{29}$, ganhar as competições da festa do $\mathrm{Mr}$ Burns ${ }^{30}$. Além disso, o garoto não é apático, não está apenas vivendo um dia atrás do outro: ele traça linhas desejantes que quer afirmar em ato e toma posse da sua vida, como quando nocauteia a babá bandida e a entrega para a polícia ${ }^{31}$; quando se esforça para ganhar o torneio de mini-golfe ${ }^{32}$ ou faz limonada para vender e pequenos serviços domésticos, como forma de juntar dinheiro a fim de comprar o gibi que tanto cobiça ${ }^{33}$.

\footnotetext{
${ }^{28} 2.08$ - Bart, the Daredevil

${ }^{29} 1.12$ - Krusty Gets Busted

${ }^{30} 1.04$ - There's No Disgrace Like Home

${ }^{31} 1.13$ - Some Enchanted Evening

32 2.06 - Dead Putting Society

${ }^{33} 2.21$ - Three Men and a Comic Book
} 
E, não raramente, as atitudes de Bart acabam por mudar a rotina da cidade inteira: ainda que o resultado nem sempre seja positivo para todos os envolvidos; consideramos essas atitudes como um exercício em fazer, do comum, uma obra-de-arte; assim, Bart acaba por redimensionar uma situação, tornando-a inesquecível e elevando-a a um grau que não é comumente atingido na vida dos habitantes de Springfield. Como exemplos destas atitudes, podemos citar a decapitação da estátua do patrono da cidade ${ }^{34}$, a vez em que ele consegue fazer o nerd Martin se tornar popular na escola ${ }^{35}$ e quando ele divulga a foto de seu pai dançando com uma stripper ${ }^{36}$.

Aliás, o que transparece na análise de Bachini e de Conrad é um sentido implícito de juízo, pelo qual ambos desejam colocar Bart em uma posição fixa, ou seja, ambos, mesmo navegando nas turvas marés nietzschianas não abandonam o senso identitário de seleção e classificação. Nesse sentido, podemos inferir que Bart, assim como Bartleby, mesmo emanando uma série de marcas identitárias, não podem ser fixados como niilistas; aliás, ambos não podem ser fixados: "preferem não"! Ou seja, com os exemplos apresentados, e com esse excerto argumentativo desejamos confrontar a classificação de Bart como niilista. Bart não pode ser classificado como niilista, pois o próprio Bart escolhe diferente, quando escolhe vir a ser tudo o que pode, mesmo que isso seja inconforme à conformidade vigente.

Assim, exploramos a possibilidade dos deslocamentos de Bart na direção dessa ideia nietzschiana de Superman. Talvez, a ideia de Bartman, o super-herói que ele imagina ser, com capa e máscara, possa funcionar como uma condição de possibilidade de um deslocamento em um estágio intermediário entre o comum e o extraordinário, entre aqueles que deixam os dias passarem por si e aqueles que fazem seus dias valerem a pena. Bart pode ser visto com um exemplo, naquele universo amarelado, de como tentar conduzir sua existência para a transcendência: de um modo e de outro, suas atitudes serão sempre lembradas pelos habitantes da cidade e ele está sempre tentando ultrapassar seus próprios limites, sem apegar-se àquelas convenções cotidianas e socialmente estabelecidas, que fornecem forma a vida dos outros personagens, que os agrupa por similitudes e lhes dá conforto e estabilidade: Bart ouve música durante as aulas de catequese ${ }^{37}$ e debocha do próprio pai quando o derrota inúmeras vezes no videogame $^{38}$.

O primogênito dos Simpsons, ao seu modo, vem a ser, então, alguém que não liga para as tradições estabelecidas e que não desperdiça uma oportunidade de tornar o instante em que vive em algo singular. Bartman, desse modo, coloca-se mais perto do limite que enseja um Superman nietzschiano do que um representante do niilismo, porquanto Bart afirma da vida as possibilidades que lhe se apresentam. Nesse sentido, tanto Bart quanto Bartleby exploram o conceito de Nietzsche, tensionando os conceitos de moral, niilismo e super-homem; o que os desloca a um limite-do-homem, cuja experiência movimenta forças afirmativas de resistência às forças reativas de sujeição. Esse limite-do-homem que Bart e Bartleby experimentam, acontece pela singularidade das suas escolhas frente às situações que lhe desejam impor formas e normas.

\footnotetext{
341.08 - The Telltale Head

${ }^{35} 2.01$ - Bart Gets an F

${ }^{36} 1.10$ - Homer's Night Out

371.08 - The Telltale Head

${ }^{38} 1.06$ - Moaning Lisa
} 
Bart e Bartleby conquistam a possibilidade de decidirem o quanto e quando desejam ou não serem senhores ou escravos, de si e dos outros.

\section{CONSIDERAÇÕES FINAIS: ALÉM DA FAMÍLIA AMARELA}

Gostaríamos de ter analisado outras temporadas de Os Simpsons e colher mais exemplos que corroborassem as nossas ideias, contudo acreditamos ter conseguido articular um conjunto de elementos suficientes para defendê-las.

Tão importante quanto a filosofia de Nietzsche estudada e, de algum modo, reverberada junto à família Simpson, é a ideia que este trabalho tensiona, qual seja, a possibilidade de procurar novas perspectivas para as relações que compõem o espaço-tempo de sala de aula. Esperamos, com este artigo, poder, de algum modo, aguçar o interesse no leitor por esta tríade: o estudo da filosofia, a inventividade do desenho (que, apostamos, prestar-se-ia ainda para as mais diversas análises, inclusive de conteúdos distintos) e a disposição para buscar diferentes formas de potencializar aprendizagens.

Neste texto, procuramos mostrar como os conceitos nietzschianos de moral, niilismo, e Super-Homem podem funcionar na articulação e na feitura de uma vida enquanto obra-de-arte, bem como, de fontes externas aos livros de filosofia, como forma de produzir percursos de produção de modos outros de pensar e significar a realidade. Nesse sentido, pensamos que, a partir desta experiência, professores, alunos, e quem mais tiver interesse, podem aventurar-se pela filosofia de Nietzsche para além da família amarela; ou seja, o modo de funcionamento dessa experiência pode ser extrapolado para outros meios: programas da TV, filmes, livros e situações do dia a dia que são relatadas nos jornais ou revistas. Desse modo, pode-se se compor um conjunto de perspectivas e discussões mais bem-humoradas com a Filosofia, como forma de pensar outros modos de envolver e implicar os conceitos filosóficos à vida cotidiana. Recorrer, nesse caso, a um mundo imaginário não é nenhum demérito; mas, pelo contrário, um ato de invenção, uma aventura fabulatória pela qual a Filosofia entrecruza suas linhas de pensamento e permeia distintas manifestações da cultura humana - neste caso, um desenho animado. Bart, Bartleby, Nietzsche, de algum modo, pelo encontro do acaso nesse texto, acabam por compor outra tríade: desenho animado, literatura e filosofia, que se entrelaça em outro território, que pode compor outros contornos, outras perspectivas, outros modos de ler e escrever a vida, inclusive em uma obra-de-arte.

\section{REFERÊNCIAS}

BACHINI, D. I Simpsons e la Filosofia. Disponível em: <skuola.tiscali.it/tesine/13412-simpson-e-filosofia.doc>. Acesso em: 21 mai. 2009.

CAMPOS, H. de. (2013) Haroldo de Campos - Transcriação. In: M. Tápia e T. M. Nóbrega (Org.). São Paulo: Perspectiva

COELHO, F. L. B.; RODRIGUES, R. A. Ética, Moral e Moralidade: Perspectivas a partir do Seriado "Os

Simpsons".

Disponível

em: 
<http://www.unifra.br/eventos/jornadaeducacao2006/2006/pdf/artigos/filosofia/\%C3\%89TI CA,\%20MORAL\%20E\%20MORALIDADE.pdf>. Acesso em: 21 de jul. 2016.

CONRAD, M. T. (2007). Assim falava Bart: Nietzsche e as virtudes de ser mal. In: SKOBLE, A. J.; CONRAD, M. T.; IRWIN, W. (Orgs.) Os Simpsons e a Filosofia (Trad. M. M. Leal). São Paulo: Madras.

Deleuze, G. (2010). Conversações (1972-1990) (Trad. P. P. Pelbart). (2ạ. Ed.). São Paulo: Ed. 34.

DELEUZE, G. (2001). Nietzsche e a Filosofia (Trad. A. M. Magalhães). Porto: Rés-Editora.

DELEUZE, G. (2010). Conversações (1972-1990) (Trad. P. P. Pelbart). (2ª. Ed.). São Paulo: Ed. 34.

DELEUZE, G. (2011). Crítica e Clínica (Trad. P. P. Pelbart). (2a . Ed.). São Paulo: Ed.34.

DELEUZE, G. e GUATTARI, F. (1995a). Mil platôs: capitalismo e esquizofrenia. vol. 1. (Trad. A. Guerra Neto e C. Pinto Costa). São Paulo: Ed. 34.

DELEUZE, G. e GUATTARI, F. (1995b). Mil platôs: capitalismo e esquizofrenia. vol. 2. (Trad. A. L. de Oliveira e L. C. Leão). São Paulo: Ed. 34.

DELEUZE, G. e GUATTARI, F. (1996). Mil platôs: capitalismo e esquizofrenia. vol. 3. (Trad. A. Guerra Neto, A. L. de Oliveira; L. C. Leão e S. Rolnik). São Paulo: Ed. 34.

DELEUZE, G. e GUATTARI, F. (1997a). Mil platôs: capitalismo e esquizofrenia. vol. 4. (Trad. S. Rolnik). São Paulo: Ed. 34.

DELEUZE, G. e GUATTARI, F. (1997b). Mil platôs: capitalismo e esquizofrenia. vol. 5. (Trad. P. P. Pelbart e J. Caiafa). São Paulo: Ed. 34.

FOUCAULT, M.(2009). Vigiar e Punir: nascimento da prisão. Rio de Janeiro: Vozes.

NIETZSCHE, F. (2009). Genealogia da Moral (Trad. P. C. de Souza). São Paulo: Companhia das Letras.

SAUTET, M.; BOUSSIGNAC, P. (1989). Nietzsche para Iniciantes. São Paulo: Brasiliense.

\section{DVDS ASSISTIDOS}

Os Simpsons - Primeira Temporada Completa. 3 DVDs. Distribuição no Brasil: Fox, 2001.

Os Simpsons - Segunda Temporada Completa. 4 DVDs. Distribuição no Brasil: Fox, 2002. 